\title{
Both the Quality and Positioning of the Night Interruption Light are Important for Flowering and Plant Extension Growth
}

\author{
Yoo Gyeong Park ${ }^{1}$ Byoung Ryong Jeong ${ }^{1,2,3}$
}

Received: 8 November 2018 / Accepted: 1 July 2019 / Published online: 10 July 2019

(c) The Author(s) 2019

\begin{abstract}
Chrysanthemum (Dendranthema grandiflorum Kitamura), a qualitative short-day plant, does not produce flowers when the night length is shorter than a cultivar-dependent critical value. Flowering is effectively inhibited when the required uninterrupted night period is broken by short periods of exposure to night interruption lights (NILs). The effects of the quality and positioning of the NIL on the morphogenesis, flowering, and photoperiodic gene expressions of chrysanthemum were investigated. Blue (NI-B), red (NI-R), far-red (NI-Fr), and white (NI-W) light-emitting diodes (LEDs) at an intensity of $10 \mu \mathrm{mol} \mathrm{m}^{-2} \mathrm{~s}^{-1}$ photosynthetic photon flux density (PPFD) were used to interrupt the dark period or plants grown in a closed walk-in growth chamber at night for a total of $4 \mathrm{~h}$. The NILs were positioned to illuminate either the shoot tip, youngest mature leaf (vigorously growing third leaf from the shoot tip), or old leaf (third leaf from the stem base). The NI-R on the shoot tip and all NI-Fr treatments increased the plant extension growth, to a similar height observed in plants in long-day (LD) treatments. Extension growth was generally suppressed for plants in the NI-B, and plant height was the smallest when NI-B was shed onto the old leaf. Plants in all NIL treatments except NI-Fr showed a negative correlation between the plant height and the age of the leaf (or tissue) exposed to the NIL. Flowering was observed for plants in all treatments except for NI-R shed onto the shoot tip. The transcriptional factor PHYA was slightly expressed in plants which showed a flowering response. However, the $C R Y 1, P H Y B$, and TFL was not expressed to levels reported previously, and the reason for low expression of these genes in these plants may be due to a combined effect of these genes with other flowering promoting and/or inhibiting genes. These results suggest that both the NIL quality and the age of the leaf (or tissue) exposed to the NIL affect the morphogenesis, flowering, and expression of transcriptional factors. Moreover, the previously known effects of the NIL quality on the morphogenesis as well as the vegetative to reproductive phase transition of plants were the most pronounced when the NIL irradiated the shoot tip, and the least pronounced when the NIL was shed onto the old leaf. Therefore, it seems that not only the appropriate quality, but also the appropriate positioning of the NIL, is important for optimizing flowering and plant extension growth.
\end{abstract}

Keywords Blue LED $\cdot$ Chrysanthemum $\cdot$ Floral signal $\cdot$ Lighting position $\cdot$ Light quality $\cdot$ Photomorphogenesis

$\begin{array}{ll}\text { Abbreviations } \\ \mathrm{B} & \text { Blue } \\ \text { CRY1 } & \text { Cryptochrome 1 } \\ \text { CRY2 } & \text { Cryptochrome 2 }\end{array}$

Byoung Ryong Jeong

brjeong@gmail.com; brjeong@gnu.ac.kr

1 Institute of Agriculture and Life Science, Gyeongsang National University, Jinju, Republic of Korea

2 Division of Applied Life Science (BK21 Plus Program), Graduate School, Gyeongsang National University, Jinju, Republic of Korea

3 Research Institute of Life Science, Gyeongsang National University, Jinju, Republic of Korea

$\begin{array}{ll}\text { Fr } & \text { Far-red } \\ \text { LD } & \text { Long-day } \\ \text { LEDs } & \text { Light-emitting diodes } \\ \text { NI } & \text { Night interruption } \\ \text { NIL } & \text { Night interruption light } \\ \text { OL } & \text { Old leaf } \\ \text { PCR } & \text { Polymerase chain reaction } \\ \text { PHYA } & \text { Phytochrome A } \\ \text { PHYB } & \text { Phytochrome B } \\ \text { PPFD } & \text { Photosynthetic photon flux density } \\ \text { R } & \text { Red } \\ \text { SD } & \text { Short-day } \\ \text { ST } & \text { Shoot tip } \\ \text { TFL1 } & \text { TERMINAL FLOWER 1 }\end{array}$

Fr Far-red

LD Long-day

LEDs Light-emitting diodes

NI Night interruption

NIL Night interruption light

OL Old leaf

PCR Polymerase chain reaction

PHYA Phytochrome A

PHYB Phytochrome B

PPFD Photosynthetic photon flux density

R Red

SD Short-day

TFL1 TERMINAL FLOWER I 
W White

YL Youngest mature leaf

\section{Introduction}

The light quality imposes important effects on the morphogenesis, photosynthesis (Kitazaki et al. 2018), and flowering (Liao et al. 2014) of plants. The growth and development of plants throughout their life cycles are controlled by photoreceptors; furthermore, photoreceptors monitor the light environment and help time key developmental transitions such as germination and flowering initiation (Kami et al. 2010). Plants sense the light quality via photoreceptors, which are categorized as phytochromes, cryptochromes, phototropins, members of the Zeitlupe (ZTL/FKF1/LKP2) family, and the UV-B-absorbing UVR8, which collectively control the photomorphogenesis over a wide range of wavelengths (Lin 2000; Takemiya et al. 2005). Among the photoreceptors, phytochromes are sensitive to red (R) and far-red (Fr) lights, whereas cryptochromes and phototropins absorb blue (B) light and UV-A lights (Lin 2000). Cryptochromes affect early growth, early establishment, stem elongation, and the control of seedlings' photoperiodic responses (Kimura and Kagawa 2006; López-Juez et al. 2007). Phototropins (two exist in Arabidopsis thaliana L.) play roles in the phototropism, control of chloroplast light-avoidance and accumulation movements, inhibition of rapid hypocotyl growth, stomatal aperture, and leaf expansion (Kimura and Kagawa 2006; López-Juez et al. 2007).

Night interruption (NI) during short-day (SD) seasons effectively accelerated the flowering of long-day (LD) plants that allowed for an earlier marketing or seed production and, under naturally LD conditions, delayed the flowering of SD plants (Hamamoto et al. 2005; Oh et al. 2013). Recent studies reported that even low-intensity NI was effective in controlling the flowering of certain plants (Kim et al. 2011; Ochiai et al. 2015; Park et al. 2015). According to the literature, Cymbidium aloifolium L. photosynthesized during a low-intensity, 4-h NI with 3-5 $\mu \mathrm{mol} \mathrm{m} \mathrm{m}^{-2} \mathrm{~s}^{-1}$ photosynthetic photon flux density (PPFD), an intensity slightly higher than that of moonlight, suggesting that the increased growth and accelerated flowering with NI are attributed to the increased net photosynthesis (Kim et al. 2011).

It is reported that some species display varying flowering responses to the NIL quality. In the LD plant Petunia hybrida Vilmorin, flowering was promoted by green, R, Fr, and white (W) lights, and inhibited by B light, implying that the light quality has different effects on the NI-induced day extension (Park et al. 2016). In the day neutral plant Pelargonium $\times$ hortorum L.H. Bailey, NI with Fr light delayed flowering (Park et al. 2017). In the SD plant Dendranthema grandiflorum Kitamura, NI with R light was the most effective in inhibiting flowering, while NI with B light and NI with Fr light did little to inhibit flowering (Higuchi et al. 2012). Previous studies irradiated the NIL only onto the plant canopy or shoot tips to control flowering. No reports have yet been published on the effects of position of the NIL shed on the plant on the morphogenesis and flowering in any plants including SD plants. And this study was conducted with a typical SD plant as a model as compared to our previous studies conducted with LD and day neutral plants as the models.

We hypothesized that, as described in many textbooks, light quality and certain positioning only, especially a certain quality NIL irradiated the shoot tip only, at a low intensity for $4 \mathrm{~h}$ would affect morphogenesis and flowering, either synergistically or antagonistically. Based on the fact that flower formation is initiated by the apical meristem's transition from a vegetative to a reproductive phase and that the quality of the 4-h low-intensity NIL affects the morphogenesis and flowering of plants, this study focused on the effects of the quality and positioning (shoot tip, youngest mature leaf, and old leaf) of the NIL on the morphogenesis and flowering of a qualitative SD plant, D. grandiflorum Kitamura 'Gaya Yellow,' with possible applications to floricultural crop production in mind.

\section{Materials and Methods}

\section{Plant Materials and Growth Conditions}

Spray-type chrysanthemum cuttings, (Dendranthema grandiflorum Kitamura 'Gaya Yellow,' a qualitative SD plant), were stuck in 50-cell plug trays with a commercial medium (Tosilee Medium, Shinan Grow Co., Jinju, Korea) and were placed on a glasshouse bench for rooting. Twelve days after sticking, rooted cuttings were transferred to a closed walk-in growth chamber $(7700 \mathrm{~cm}$ long $\times 2500 \mathrm{~cm}$ wide $\times 2695 \mathrm{~cm}$ high, Green Industry Co. Ltd., Changwon, Korea) maintained at an air temperature setpoint of $20 \pm 1{ }^{\circ} \mathrm{C}$, a relative humidity of $60 \pm 10 \%$, and with a 16 -h photoperiod of $140 \mu \mathrm{mol} \mathrm{m} \mathrm{m}^{-2} \mathrm{~s}^{-1}$ PPFD (LD condition) provided by fluorescent lamps (F48T12-CW-VHO, Philips Co., Ltd., Eindhoven, The Netherlands). This growth chamber was specially designed to blow in conditioned air horizontally into the growing spaces through numerous uniformly distributed holes. The $\mathrm{CO}_{2}$ concentration was maintained at atmospheric levels $\left(350 \pm 50 \mu \mathrm{mol} \mathrm{mol}^{-1}\right)$ by supplementation from a compressed gas tank. Following 12 days of acclimatization, the plants (approximately $10.2 \mathrm{~cm}$ tall) were subjected to the photoperiodic light treatments. After planting, plants were fertigated with a greenhouse multipurpose nutrient solution formulated as shown in Park et al. (2015). A randomized complete block design with 3 replications 
with 2 plants each was employed. The treatment locations in a controlled environment were randomly mixed between replications to minimize position effects.

\section{Photoperiodic Light Treatments}

A light intensity of $180 \mu \mathrm{mol} \mathrm{m}^{-2} \mathrm{~s}^{-1}$ PPFD via white (W) LEDs (MEF50120, More Electronics Co. Ltd., Changwon, Korea) was supplied during the photoperiod to grow the plants. Zeitgeber Time (ZT), which is a $24-\mathrm{h}$ time-scale in which "light on" is ZT 0 in photoperiodic research, light was provided between ZT0 and ZT16, and between ZT0 and ZT10 in LD and SD conditions, respectively. Night interruptions were provided to SD conditions from $\mathrm{Zt} 15$ to $\mathrm{Zt} 19$. The critical day length required for flowering in the SD plant used throughout this study was $12 \mathrm{~h}$, and therefore, a 14-h period of uninterrupted darkness was sufficient to initiate flowering. However, SD with $16 \mathrm{~h}$ of darkness was used in this study to confirm a clear flowering response. The photoperiod was started at 08:00 every day in all treatments. LD and uninterrupted SD served as the control. NI was constructed by $10 \mu \mathrm{mol} \mathrm{m}{ }^{-2} \mathrm{~s}^{-1}$ PPFD LEDs with either blue (B, $450 \mathrm{~nm})$, red (R, $660 \mathrm{~nm})$, far-red (Fr, $730 \mathrm{~nm})$, or white (W, $400-700 \mathrm{~nm}$, with $28 \% \mathrm{~B}, 37 \% \mathrm{R}$, and $15 \% \mathrm{Fr}$ ) wavelengths, which were, respectively, designated as NI-B, NI-R, NI-Fr, and NI-W (Figs. 1, 2). The average PPFD of each treatment was measured using a digital photometer (HD2102.1, Delta OHM, Padova, Italy) at a $20-\mathrm{cm}$ distance above the bench top, and was adjusted to the same before NI treatments were initiated. The light spectral distribution was scanned using a spectroradiometer (USB 2000 Fiber Optic Spectrometer, Ocean Optics Inc., Dunedin, FL, USA; wavelength detection ranges of 200 to $1000 \mathrm{~nm}$ ) $25 \mathrm{~cm}$ above the bench top at 1-nm wavelength intervals. The spectral distribution and

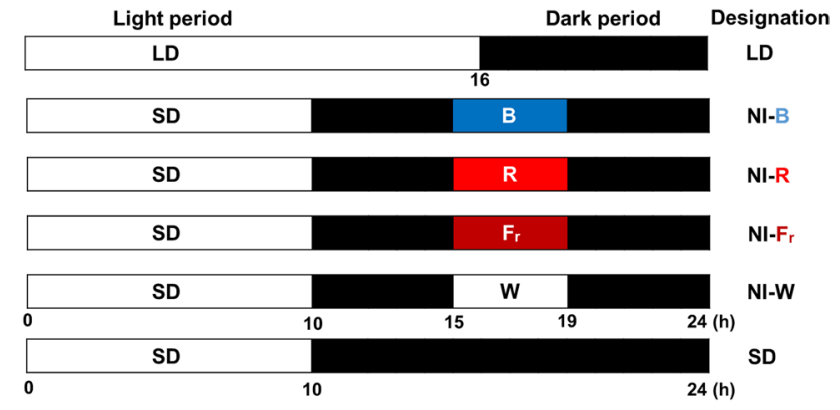

Fig. 2 A representative image of the night interruption light (NIL) quality and positioning by light-emitting diodes (LEDs). The NI and positioning treatments, provided by LEDs, used in this study and the NIL qualities used for 4-h a day during the dark period: NI-B, blue; NI-R, red; NI-Fr, far-red; and NI-W, white. The LD and SD indicate 16-h long day and 10-h short day, respectively

characteristics measured at three locations within the plant growing areas in each treatment are shown in Fig. 1. The NIL was shed onto either the shoot tip, youngest mature leaf (vigorously growing third leaf from the shoot tip), or old leaf (third leaf from the stem base) (Fig. 3). In order to minimize the interference of other light sources and to illuminate specific areas with the NIL, a chip of specified LED light was fixed inside a rectangular column $(20 \mathrm{~mm} \times 20 \mathrm{~mm} \times 40 \mathrm{~mm}$ in length) of black cardboard wrapped with reflective aluminum foil as shown in Fig. 3.

\section{Data Collection and Statistical Analysis}

Forty-four days after initiating the photoperiodic treatments, the following data were collected: plant height, number of leaves per plant, chlorophyll content, dry mass, fresh and dry weights of the shoot and root, time from treatment initiation

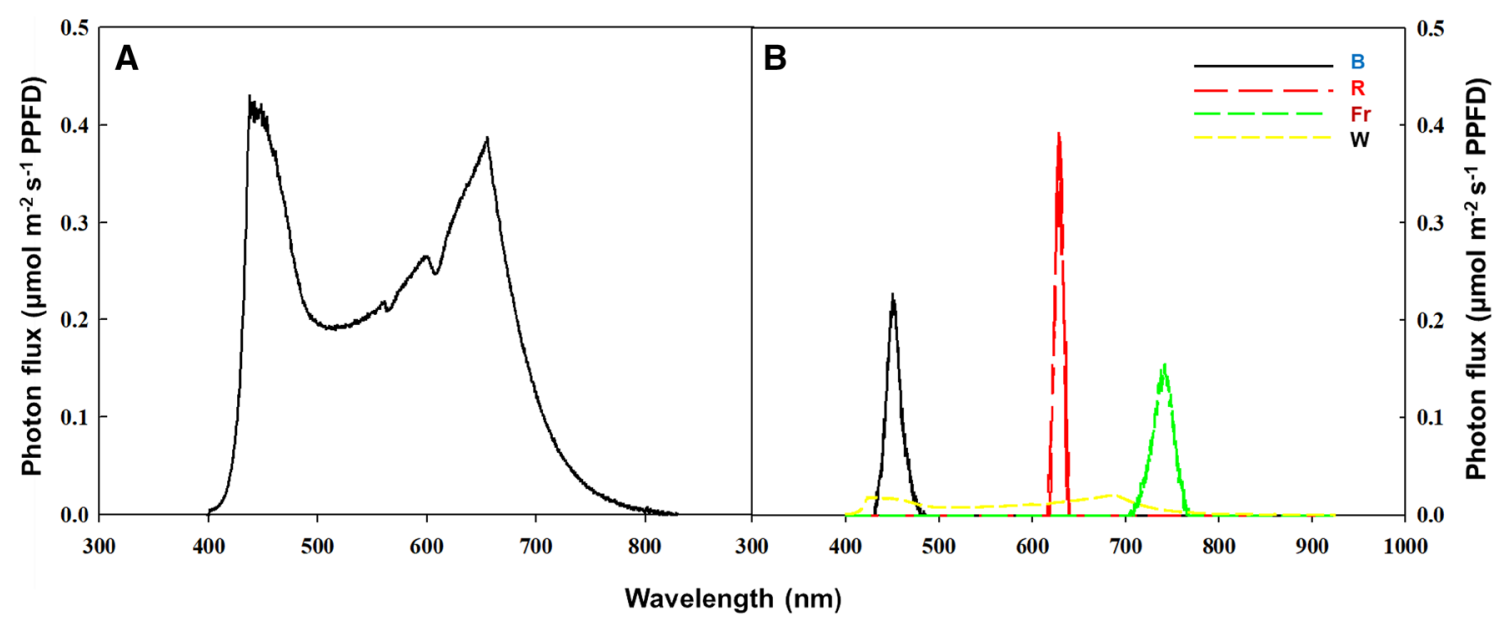

Fig. 1 Spectral distribution of the night interruption light (NIL). The spectral distribution of light used in a closed walk-in growth chamber: white light-emitting diodes (LEDs) used as daily light (a) and differ- ent LEDs ( $B$ blue, $R$ red, $F r$ far-red, $W$ white) used as NILs (b) (Color figure online) 
Fig. 3 Photos of the night interruption light (NIL) positioning. The effects of the NIL quality and positioning provided at $10 \mu \mathrm{mol} \mathrm{m}{ }^{-2} \mathrm{~s}^{-1}$ PPFD on the morphogenesis and flowering of the photoperiodic floricultural plants: a shoot tip; $\mathbf{b}$ youngest mature leaf; and $\mathbf{c}$ old leaf
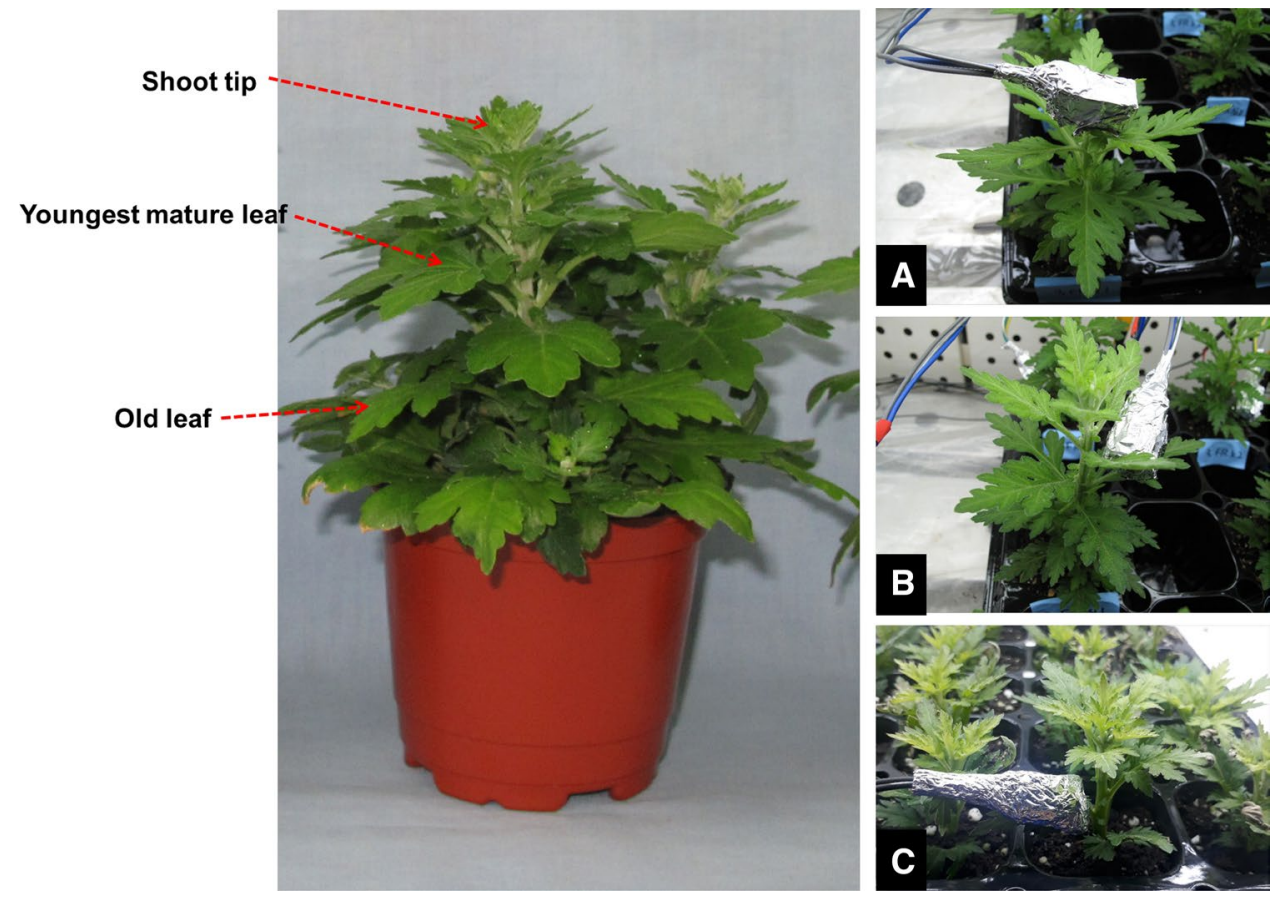

to visible flower buds, number of flowers and flower buds per plant (hereafter designated as the "number of flowers"), and the expression of important photoreceptor genes. The number of leaves per plant was measured by counting all leaves which are longer than $1 \mathrm{~cm}$ in length. The fresh weight was measured by an electronic scale (EW 220-3NM, Kern and Sohn GmbH., Balingen, Germany). Dry weight was measured after drying the divided samples of the shoot and root for $72 \mathrm{~h}$ in a drying oven (Venticell-222, MMM Medcenter Einrichtungen $\mathrm{GmbH}$., Munich, Germany) at $70^{\circ} \mathrm{C}$. The leaf area was measured with a leaf area meter (LI-3000, LI-COR Inc., Lincoln, NE, USA). For chlorophyll content estimation, $10 \mathrm{mg}$ of fresh leaf samples was taken from the young fully developed leaves. Chlorophyll was extracted using $80 \% 4{ }^{\circ} \mathrm{C}$ acetone. The absorbance of the supernatant was measured at 663 and $645 \mathrm{~nm}$ using a spectrophotometer (Biochrom Libra S22, Biochrom Co. Ltd., Holliston, MA, USA) after a centrifugation at $3000 \mathrm{rpm}$. Calculations were done according to the method by Dere et al. (1998). The statistical analysis was carried out using the statistical analysis program (SAS 9.1, SAS Institute Inc., Cary, NC, USA). The experimental results were subjected to an analysis of variance (ANOVA) and Tukey's multiple range test. Graphing was performed with a graphic program (SigmaPlot 12.0, Systat Software Inc., San Jose, CA, USA).

\section{Total RNA Isolation, cDNA Synthesis, and Real-Time Polymerase Chain Reaction (PCR) of Selected Genes}

For total RNA extraction, the most recently matured leaf was collected 30 days after the initiation of the photoperiodic light treatments, when plants had already developed visible flower buds, unless they were grown in LD or with NI-R shed onto the shoot tip. The most recently matured leaf was collected at 09:00, $1 \mathrm{~h}$ after the daily light treatment initiation. This decision was based on the fact that at this time of the day, photosynthetic rates are high. Independent PCRs with equal amounts of cDNA were performed using primers of Phytochrome A (PHYA), Phytochrome B (PHYB), cryptochrome 1 (cryl), and TERMINAL FLOWER 1 (TFL1) genes of the sequence (Table 1). Actin was used as an internal control, as it is commonly used to normalize

Table 1 List of the primers used to quantify the levels of gene expression

\begin{tabular}{llll}
\hline Gene & Accession no. & Forward primer & Reverse primer \\
\hline PHYA & EU915082 & 5'-GACAGTGTCAGGCTTCAACAAG-3' & 5'-ACCACCAGTGTGTGTTATCCTG-3' \\
$P H Y B$ & NM_127435 & 5'-GTGCTAGGGAGATTACGCTTTC-3' & 5'-CCAGCTTCTGAGACTGAACAGA-3' \\
CRY1 & NM_116961 & 5'-CGTAAGGGATCACCGAGTAAAG-3' & 5'-CTTTTAGGTGGGAGTTGTGGAG-3' \\
TFL1 & AB839767 & 5'-ACAACGGACTCCTCATTTGG-3' & 5'-CGCGAAACTACGAGTGTTGA-3' \\
Actin & AB205087 & 5'-CGTTTGGATCTTGCTGGTCG-3' & 5'-CAGGACATCTGAAACGCTCA-3' \\
\hline
\end{tabular}


molecular expression studies. The relative expression of each gene was determined using the $2^{-\Delta \Delta \mathrm{Ct}}$ method (Livak and Schmittgen 2001). Then, the individual gene expression values of the treated plants were divided by the mean gene expression level for plants in SD at each sampling date. The methods used for total RNA isolation and semi-quantitative real-time PCR analysis of selected genes were the same as those described in Park et al. (2015).

\section{Results}

\section{Morphogenesis}

Plants grown in LD were taller than those in SD (Fig. 4a). Compared to plants grown in SD, plants in NI-R and NI-Fr were taller, and plants in NI-B were shorter. In all NI treatments except NI-Fr, the plant height was negatively correlated with the age of the leaf (or tissue) exposed to the NIL. The greatest plant height was observed for plants in NI-Fr applications, regardless of where the NIL was shed onto. Plant height was the smallest when NI-B was shed onto the old leaf as compared to SD.

For all NI treatments except NI-R, the dry mass of plant was negatively correlated with the age of the leaf (or tissue) where the NIL was applied (Fig. 4b). The dry mass of plants grown with NI-B or NI-Fr shed onto the old leaf was $26 \%$ or $31 \%$ lower, respectively, than that of plants grown in SD. The lower dry mass of plants grown with NI-B shed onto the old leaf (Fig. 4b) may be related to the distinctively shorter plants (Fig. 4a). Plants with NI-Fr shed onto the old leaf had the lowest dry mass, which may be related to the overgrowth or stretchiness.

The highest number of leaves was observed for plants in the LD, and plants in NI-W had the highest number of leaves of all plants in NI treatments (Fig. 4c). The lowest number of leaves per plant was observed for plants whose old leaves were illuminated by NI-B. For NI-R and NI-W, illumination of the shoot tip resulted in the greatest observed leaf areas (Fig. 4d), but when shed onto the youngest mature leaf or old leaf, leaf expansion or mean leaf area was drastically suppressed (Fig. 4e). The NI-B and NI-Fr positioning did not seem to affect the leaf area. Of all NIL qualities and positioning considered in the experiment, the chlorophyll content was the lowest when NI-R was shed onto the shoot tip (Fig. 4f). The NI-Fr seemed to have no significant effects on the chlorophyll content regardless of where on the plant it was shed onto.

\section{Flowering}

Flowering was induced by all treatments except LD and NI-R shed onto the shoot tip (Figs. 4g, h, 5a, b). Moreover, the time from treatment initiation to visible flower buds was shorter for plants whose old leaves were illuminated by NI-Fr or NI-B as compared to SD, and was longer for plants shed by NI-R on the youngest mature leaf or old leaf and NI-W shed onto the shoot tip, youngest mature leaf, or old leaf, than plants in SD (Fig. 4g). When NI-R was shed onto the youngest mature leaf, the number of flowers per plant was $63 \%$ higher than that observed in SD (Fig. 4h).

\section{Gene Expression Analysis}

The expression of PHYA was significantly reduced by most of the treatments as compared to SD (Fig. 6a), whereas expression of $P H Y B$ was enhanced by most of the treatments as compared to SD (Fig. 6b). For the plants in SD, the expressions of PHYA and PHYB were the greatest and lowest, respectively (Fig. 6a, b). CRY1 was highly expressed in plants in SD and reduced in all NI treatments except NI-W shed onto the old leaf (Fig. 6c). TFL1 was enhanced in all NI treatments as well as LD, and the highest level of TFL1 expression was observed in plants grown with NI-B shed onto the young mature leaf (Fig. 6d).

\section{Discussion}

\section{Plant Height}

Light capture is strongly dependent on the light absorption characteristics of leaves; pigment composition, thickness, tissue porosity, chloroplast orientation at different positions (ages) on the stem, and optical properties of leaves all affect the light absorption characteristics (van Ieperen 2012). Among the plants grown in NI-B, NI-R, and NI-W, but NI-Fr, it was observed that the younger the leaves that were exposed to the NIL (Fig. 4a), the incrementally taller the plants were. This means that NIL applied to younger leaves promotes, while that applied to older leaves suppresses stem elongation, suggesting different preferable sites of NIL application depending on the type of crops produced such as cut flowers and potted flowers. These changes in stem elongation were caused by decreased number of leaves or shortened time from the treatment initiation to visible flower buds in all, but NI-W shed onto the shoot tip, the reason for which is not clearly explainable.

This study shows that plants grown in NI-Fr were taller regardless of the location of light exposure, indicating that the effects of Fr light may not depend strongly on its positioning on the plant (Fig. 4a). Many species develop elongated stems and smaller leaves when they are grown in close proximity to neighboring plants, and these characteristics are known as the shade avoidance response (Hersch et al. 2014). The shade avoidance response improves a plant's reach to 


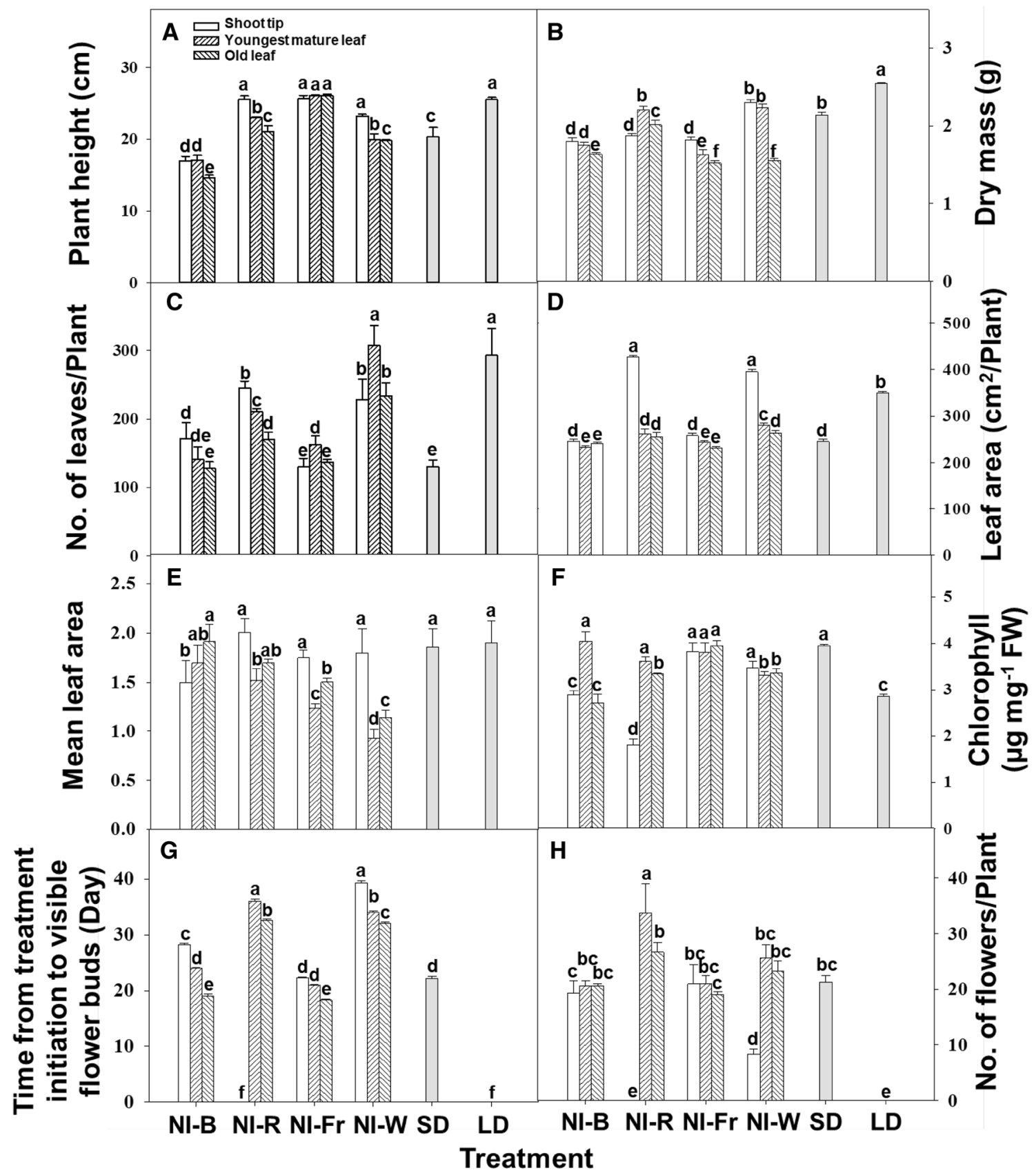

Fig. 4 The effects of the night interruption light (NIL) quality and its positioning on the plant height (a), dry mass (b), number of leaves per plant (c), leaf area per plant (d), mean leaf area (e), chlorophyll content (f), time from treatment initiation to visible flower buds (g), and number of flowers per plant (h) in Dendranthema grandiflorum 'Gaya Yellow.' The NIL qualities used for 4-h a day during the dark

light above other plants and provides a competitive advantage (Hersch et al. 2014).

The use of B light during the photoperiod to inhibit plant elongation was previously documented in chrysanthemums (Oyaert et al. 1999; Kim et al. 2004; Shimizu et al. 2006). However, the growth-suppressing effects of period: NI-B, blue; NI-R, red; NI-Fr, far-red; and NI-W, white. The LD and SD indicate 16-h long day and 10-h short day, respectively. Data are the mean \pm S.E of the three biological replicates. Means accompanied by different letters are significantly different $(P<0.05)$ according to the Tukey's studentized range test at 5\% significance level

the NIL, especially B light, are not well known. Schuerger et al. (1997) noted that B light plays a part in inhibiting the growth, changing the stem anatomy, and morphologically developing the leaves in pepper plants. Furthermore, Khattak and Pearson (2006) reported that a low level B light during the photoperiod suppressed plant growth. Our finding 
Fig. 5 The effects of the night interruption light (NIL) quality and positioning provided at $10 \mu \mathrm{mol} \mathrm{m}{ }^{-2} \mathrm{~s}^{-1}$ PPFD on the flowering of Dendranthema grandiflorum 'Gaya Yellow' measured 44 days after treatment: side view (a) and top view (b) (See Fig. 3 for details on the NIL quality). The lighting positions were $S T$ shoot tip, $Y L$ youngest mature leaf, $O L$ old leaf
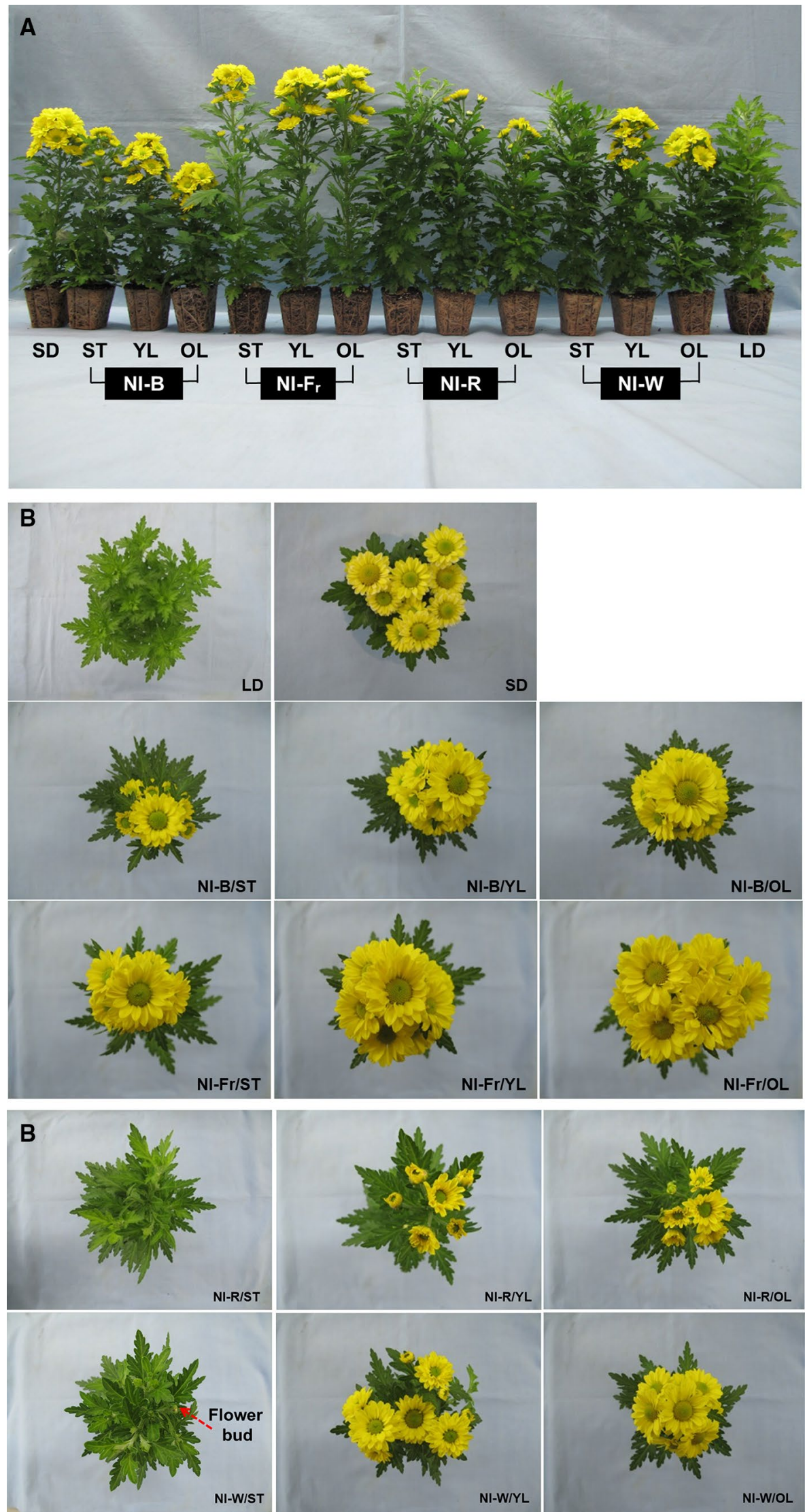


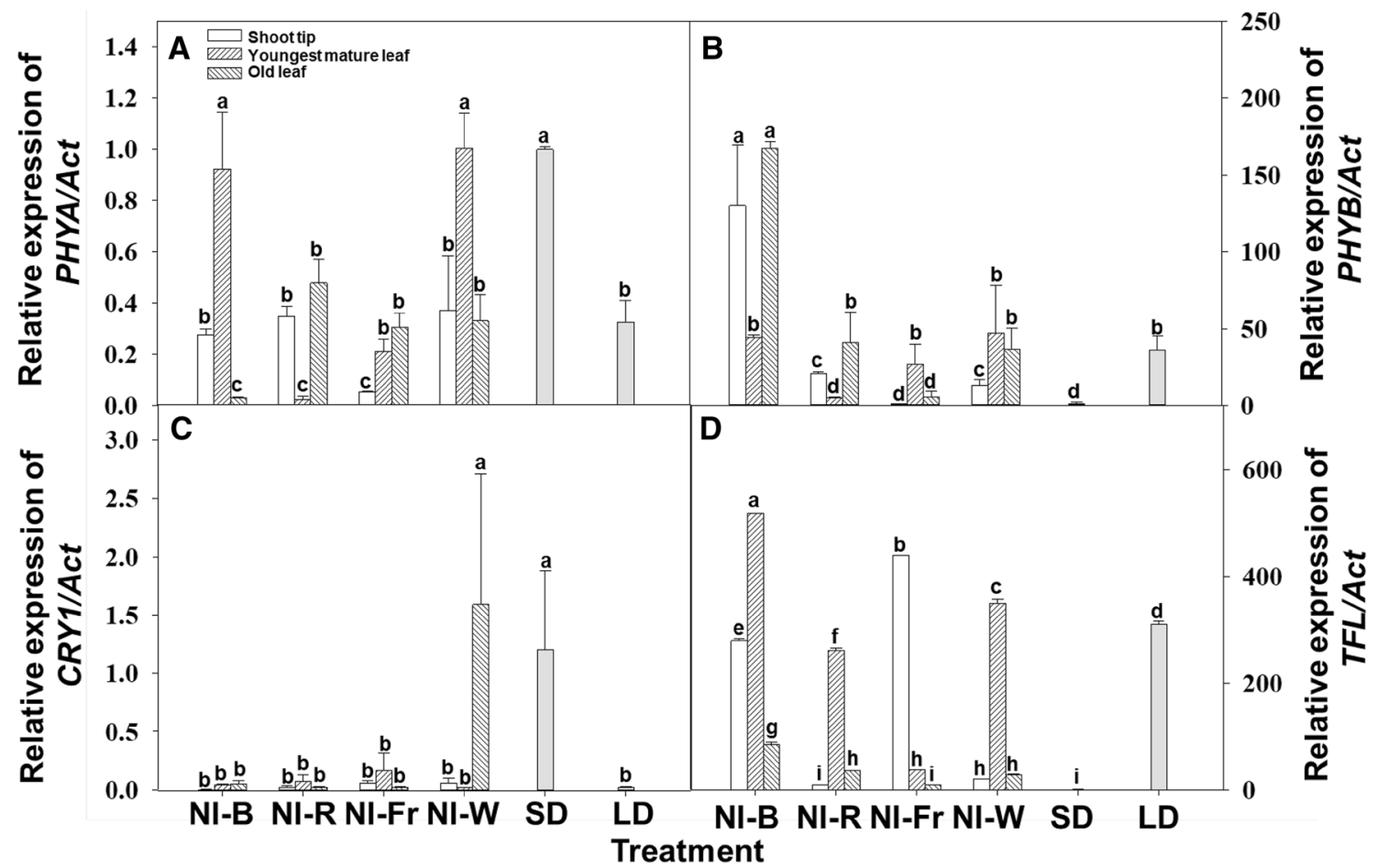

Fig. 6 The effects of the night interruption light (NIL) quality and positioning provided at $10 \mu \mathrm{mol} \mathrm{m} \mathrm{m}^{-2} \mathrm{~s}^{-1}$ PPFD on the relative gene expression by real-time PCR of PHYA (a), PHYB (b), CRY1 (c), and TFL (d) of Dendranthema grandiflorum 'Gaya Yellow' (See Fig. 1 for details on the NIL quality). The relative expression of each gene was determined using the $2^{-\Delta \Delta C t}$ method. Then, the individual gene

that NI-B may limit plant height (Fig. 4a) can help growers achieve desired compact growth, i.e., in potted flowering plants. Tewolde et al. (2016) reported that the node length of tomato plants was reduced when $\mathrm{R}$ and B LEDs were used in conjunction for inter-lighting on the lower canopy. Interlighting, which refers to directing light to lower parts of plants, on the lower plant canopy may be a possible practical method to suppress plant height, and control flowering. The $\mathrm{B}$ light inter-lighting could be more effective than combined $\mathrm{R}$ and $\mathrm{B}$ light inter-lighting in controlling the plant height, and NI-B may be a good, environmentally sound alternative to plant growth retardants which are widely used in the production of potted flowering plants.

\section{Leaf Growth}

Plants shed with NI-B or NI-Fr onto the youngest mature leaf or old leaf resulted in smaller leaf area as compared to plants in SD (Fig. 4d). This was due to the rapid switch from vegetative growth to reproductive growth in all, but NI-W shed onto the shoo tip, as the sensitivity of old leaves to NI seemed negligible in comparison to that of the shoot tip, which is in agreement with the established theory (Zeevaart expression values of the treated plants were divided by the mean gene expression level for plants in SD at each sampling date. Data are the mean \pm S.E of the three biological replicates. Means accompanied by different letters are significantly different $(P<0.05)$ according to the Tukey's studentized range test at $5 \%$ significance level

2008) who reported that florigen was the leaf-produced signal that induces floral initiation at the shoot tip.

Chlorophyll content decreased in non-flowering treatments such as plants grown with NI-R shed onto the shoot tip and LD condition in this study (Fig. 4f). Gang et al. (1992) reported that the chlorophyll content increased during the transition from vegetative to reproductive growth and decreased during maturation. Thus, in this study, the decrease in the chlorophyll content of plants in LD and plants grown with NI-R shed onto the shoot tip as compared to other treatments may be due to continued vegetative growth. This may apply to the NI-B shed onto youngest mature leaf (Fig. 4). However, in other NI-B treatments such as NI-B shed onto the shoot tip or old leaf, chlorophyll content decreased, although flowering was observed. The real reason for these decreased chlorophyll contents in plants grown with NI-B shed onto the shoot tip or old leaf is not clearly explainable.

\section{Flowering and Gene Expression}

The expression of PHYA slightly promotes flowering in plants grown with NI-B and NI-W shed onto the youngest 
mature leaf, and SD (Fig. 6a). It was speculated that $P H Y A$ can promote flowering by suppressing $P H Y B$ function and/ or by independent mechanisms. The non-flowering that was observed in LD despite high level of PHYA expression may be due to the high expression levels of $P H Y B$ and $T F L$ observed in that treatment (Fig. 6a, b, d). PHYB acts in a partially redundant manner with $P H Y D$ and $P H Y E$ to mediate the $\mathrm{R}$ light-dependent inhibition of flowering (Franklin et al. 2003; Mockler et al. 1999). However, PHYB may serve a more complex role in floral initiation than just as a simple inhibitor (Lin 2000). The $C R Y 1$ and $C R Y 2$ act redundantly to mediate the $\mathrm{B}$ light-dependent promotion of flowering (Mockler et al. 2003). Because the phyA mutant flowered late in response to a day extension with the Fr-rich incandescent light (Johnson et al. 1994), it may be speculated that PHYA may mediate the Fr light-dependent inhibition of the PHYB function (Lin 2000), analogous to the antagonistic relationship of $C R Y 2$ and $P H Y B$, and to the Fr light-dependent $P H Y A$ function in the hypocotyl development inhibition. The $C R Y 2$, in addition to its antagonism to $P H Y B$, also mediates the $\mathrm{B}$ light-dependent promotion of floral initiation. The CRY2's mediation of the B light-dependent flowering promotion is redundant with that of CRYI (Mockler et al. 1999).

The flowering is theorized to be induced when one or more of the flowering promotor genes (PHYA and CRYI) are expressed in high levels (Lin 2000; Song et al. 2013). In general, B light enhances flowering by the photoregulation of several floral induction genes (Fukuda et al. 2008). In Arabidopsis thaliana, the B light signal perceived by CRY1 or CRY2 stimulates the expression of FT and SUPPRESSOR OF OVEREXPRESSION OF CO 1 (SOCI) via increased CONSTANS (CO) protein stabilization, which subsequently induces differentiation of the meristematic tissue and early flowering (Fukuda 2013). Although it is not known whether it applies to chrysanthemums in the same manner, florigen is the hypothetical signal produced at the leaf that initiates the shoot apex flowering (Zeevaart 2008). Our findings indicate that flowering was not observed for at least 44 days of treatment for plants with NI-R shed onto the shoot tip (Fig. 5b). Unexpectedly, flowering was induced in plants with NI-R shed onto the youngest mature leaf or old leaf, indicating that the commonly known $\mathrm{R}$ light suppression of flowering during NI in SD plants may not necessarily apply in the case of NIL irradiation onto young and old leaves. Light signals stimulate photoreceptors, thereby controlling the floral induction genes (Cerdán and Chory 2003). Flowers bloom early when the 'gene switch' to initiate floral buds is turned on by a light of a specific quality. According to Higuchi et al. (2012), NI-Fr for chrysanthemum has reversed the flowering response inhibited by NI-R. Further reverse genetic approaches have elucidated the $P H Y B$-mediated inhibition of flowering in plants under NI-R and the subsequent reversion of flowering response by NI-Fr in chrysanthemum
(Higuchi et al. 2012). In addition, the knock-down of the $P H Y B$ gene resulted in the up-regulation of the flowering inducer (florigen) and down-regulation of the flowering inhibitor (antiflorigen) in chrysanthemum, and led to the extremely early flowering response (Higuchi et al. 2013). However, $P H Y B$ and TFL, both flowering inhibitors, were not highly expressed in plants in NI-R shed onto the shoot tip, although flowering was not observed (Fig. 6b). The real reason for low expression of these genes in these plants may be a combined effect of these genes with other flowering inhibiting genes such as Anti-florigenic FT/TFL1 family protein $(A F T)$, which were not investigated in this study.

The transcriptional factor $P H Y A$, a flowering promotor gene, was slightly expressed, while $C R Y 1$, another flowering promotor gene, was not expressed to an expected level in such treatments as SD and all NI treatments except NI-R shed onto the shoot tip. The overall expression patterns of photomorphogenic genes observed in this study differed from those described in previous studies (Higuchi et al. 2012, 2013). Possible explanations for this disparity are differences in the chrysanthemum genotypes used, the experimental environment, the sample collection time, the plant part from which the samples were collected, and the specific wavelengths of LEDs used in the studies.

In this study, the time after treatment initiation to visible flower buds was shortened by NI-Fr or NI-B shed onto the old leaf, and was lengthened by NI-R shed onto the youngest mature leaf or old leaf and by NI-W shed onto the shoot tip, youngest mature leaf, or old leaf. In the experiment on the effects of the NIL quality, flowering was inhibited for plants in NI-R and NI-W (Park 2014), while flowering was interrupted by NI-R treatments in the experiment on the effects of the NIL quality and positioning.

Interestingly, our experiment shows that plants with NI-R shed onto the youngest mature leaf had more flowers per plant than those in SD. This agrees with the overflow metabolism concept, where the carbon demands associated with plant growth are exceeded by the carbohydrate production (Matsuki 1996; Park et al. 2013), and is expressed in ways such as a higher number of flowers per plant due to the relatively longer duration of vegetative growth.

Our results indicated that the quality of the NIL and the age of the leaf (or tissue) exposed to the NIL affected the morphogenesis, flowering, and transcriptional factors of chrysanthemum. The plant height was related to the time from treatment initiation to visible flower buds. Leaf growth was affected when NIL was targeted onto the shoot tip. The previously known effects of the NIL quality on the vegetative to reproductive phase transition of plants were pronounced when the NIL was shed onto the shoot apex. The transcriptional factor $P H Y A$ was slightly expressed in plants which showed a flowering response. However, the CRY1, PHYB, and $T F L$ were not expressed to levels reported previously, 
and the reason for low expression of these genes in these plants may be due to a combined effect of these genes with other flowering promoting and/or inhibiting genes. The NI-R, NI-Fr, and NI-B shed onto the youngest mature leaf or old leaf could potentially control the flowering of SD plants. The NI-B shed onto the old leaf could potentially help produce desirably compact potted SD plants due to its height-suppressing characteristics. Inter-lighting the lower plant canopy could be a practical application of the results of this study to control the plant height and flowering in the production of floricultural crops.

Acknowledgements The authors are thankful to Drs. Sowbiya Muneer, Prabhakaran Soundararajan, and Young Don Chin their assistance.

Author Contributions Designed the project: BRJ and YGP; Performed the experiments: YGP; Analyzed the data: YGP; Maintained the plant factory: YGP; Took care of plants: YGP; Wrote paper: YGP and BRJ.

\section{Compliance with Ethical Standards}

Conflicts of interest The authors declare that they have no conflict of interest.

Open Access This article is distributed under the terms of the Creative Commons Attribution 4.0 International License (http://creativeco mmons.org/licenses/by/4.0/), which permits unrestricted use, distribution, and reproduction in any medium, provided you give appropriate credit to the original author(s) and the source, provide a link to the Creative Commons license, and indicate if changes were made.

\section{References}

Cerdán PD, Chory J (2003) Regulation of flowering time by light quality. Nature 423:881-885

Dere S, Gunes T, Sivaci R (1998) Spectrophotometric determination of chlorophyll $-\mathrm{a}, \mathrm{b}$ and total carotenoid contents of some algae species using different solvents. Turk J Bot 22:13-17

Franklin KA, Praekelt U, Stoddart WM, Billingham OE, Halliday KJ, Whitelam GC (2003) Phytochromes B, D, and E act redundantly to control multiple physiological responses in Arabidopsis. Plant Physiol 131:1340-1346

Fukuda N (2013) Advanced light control technologies in protected horticulture: a review of morphological and physiological responses in plants to light quality and its application. J Devel Sustain Agric 8:32-40

Fukuda N, Fujita M, Ohta Y, Sase S, Nishimura S, Ezura H (2008) Directional blue light irradiation triggers epidermal cell elongation of abaxial side resulting in inhibition of leaf epinasty in geranium under red light condition. Sci Hortic 115:176-182

Gang Z, Yu T, Banghua Y, Xiaolei L (1992) A study on the relationship between the chlorophyll content and the yield of plant of tartary buckwheat. In: Rufa L, Yongru ZMT, Jianying L, Zongwe $\mathrm{Z}$ (eds) Proceedings of 5th International Symposium Buckwheat at Taiyuan, pp 122-126

Hamamoto H, Hideo S, Tadahisa H (2005) Budding response of horticultural crops to night break with red light on alternate days. Environ Control Biol 43:21-27
Hersch M, Lorrain S, Wit M, Trevisan M, Ljung K, Bergmann S (2014) Light intensity modulates the regulatory network of the shade avoidance responses in Arabidopsis. Proc Natl Acad Sci USA 111:6515-6520

Higuchi Y, Sumitomo K, Oda A, Shimizu H, Hisamatsu T (2012) Day light quality affects the night-break response in the short-day plant chrysanthemum, suggesting differential phytochrome-mediated regulation of flowering. J Plant Physiol 169:1789-1796

Higuchi Y, Narumi T, Oda A, Nakano Y, Sumitomo K, Fukai S et al (2013) The gated induction system of a systemic floral inhibitor, antiflorigen, determines obligate short-day flowering in chrysanthemums. Proc Natl Acad Sci USA 110:17137-17142

Johnson E, Bradley M, Harberd NP, Whitelam GC (1994) Photoresponses of light-grown phyA mutants of Arabidopsis (phytochrome $\mathrm{A}$ is required for the perception of day length extensions). Plant Physiol 105:141-149

Kami C, Lorrain S, Hornitschek P, Fankhauser C (2010) Light-regulated plant growth and development. Curr Topics Devel Biol 91:29-66

Khattak AM, Pearson S (2006) Spectral filters and temperature effects on the growth and development of chrysanthemums under low light integral. Plant Growth Regul 49:61-68

Kim HH, Goins GD, Wheeler RM, Sager JC (2004) Green-light supplementation for enhanced lettuce growth under red- and bluelight-emitting diodes. Hortic Sci 39:1617-1622

Kim YJ, Lee HJ, Kim KS (2011) Night interruption promotes vegetative growth and flowering of Cymbidium. Sci Hortic 130:887-893

Kimura M, Kagawa T (2006) Phototropin and light-signaling in phototropism. Curr Opin Plant Biol 9:503-508

Kitazaki K, Fukushima A, Nakabayashi R, Okazaki Y, Kobayashi M, Mori T, Nishizawa T, Reyes-Chin-Wo S, Michelmore RW, Saito K, Shoji K (2018) Metabolic reprogramming in leaf lettuce grown under different light quality and intensity conditions using narrowband LEDs. Sci Rep 8:7914

Liao Y, Suzuki K, Yu W, Zhuang D, Takai Y, Ogasawara R, Shimazu T, Fukui H (2014) Night-break effect of LED light with different wavelengths on shoot elongation of Chrysanthemum morifolium Ramat 'Jimba' and 'Iwa No Hakusen'. Environ Control Biol 52:51-55

Lin C (2000) Photoreceptors and regulation of flowering time. Plant Physiol 123:39-50

Livak KJ, Schmittgen TD (2001) Analysis of relative gene expression data using real-time quantitative PCR and the $2^{-\Delta \Delta \mathrm{Ct}}$ method. Methods 25:402-408

López-Juez E, Bowyer JR, Sakai T (2007) Distinct leaf developmental and gene expression responses to light quantity depend on blue-photoreceptor or plastid-derived signals, and can occur in the absence of phototropins. Planta 227:113-123

Matsuki M (1996) Regulation of plant phenolic synthesis: from biochemistry to ecology and evolution. Aust J Bot 44:613-634

Mockler TC, Guo H, Yang H, Duong H, Lin C (1999) Antagonistic actions of Arabidopsis cryptochromes and phytochrome B in the regulation of floral induction. Development 126:2073-2082

Mockler T, Yang H, Yu W, Parikh D, Cheng Y, Dolan S, Lin C (2003) Regulation of photoperiodic flowering by Arabidopsis photoreceptors. Proc Natl Acad Sci USA 100:2140-2145

Ochiai M, Liao Y, Shimazu T, Takai Y, Suzuki K, Yano S, Fukui H (2015) Varietal differences in flowering and plant growth under night-break treatment with LEDs in 12 chrysanthemum cultivars. Environ Control Biol 53:17-22

Oh W, Kang KJ, Cho KJ, Shin JH, Kim KS (2013) Temperature and long-day lighting strategy affect flowering time and crop characteristics in Cyclamen persicum. Hortic Environ Biotechnol $54: 484-491$ 
Oyaert E, Volckaert E, Debergh PC (1999) Growth of chrysanthemum under coloured plastic films with different light qualities and quantities. Sci Hortic 79:195-205

Park YG (2014) Morphogenesis and flowering of photoperiodic floricultural plants in response to quality, quality shifting, and positioning of night interruption light. Ph. D. Thesis. Gyeongsang National University. http://academic.naver.com/article.naver ?doc $\_$id $=80088464$

Park YG, Oh HJ, Jeong BR (2013) Growth and anthocyanin concentration of Perilla frutescens var. acuta Kudo as affected by light source and DIF under controlled environment. Hortic Environ Biotechnol 54:103-108

Park YG, Muneer S, Jeong BR (2015) Morphogenesis, flowering, and gene expression of Dendranthema grandiflorum in response to shift in light quality of night interruption. Int J Mol Sci 16:16497-16513

Park YG, Muneer S, Soundararajan P, Manivnnan A, Jeong BR (2016) Light quality during night interruption affects morphogenesis and flowering in Petunia hybrida, a qualitative long-day plant. Hortic Environ Biotechnol 57:371-377

Park YG, Muneer S, Soundararajan P, Manivnnan A, Jeong BR (2017) Light quality during night interruption affects morphogenesis and flowering in geranium. Hortic Environ Biotechnol 58:212-217

Schuerger AC, Brown CS, Stryjewski EC (1997) Anatomical features of pepper plants (Capsicum annuиm L.) grown under red lightemitting diodes supplemented with blue or far-red light. Ann Bot 79:273-282
Shimizu H, Ma Z, Tazawa S, Douzono M, Runkle ES, Heins RD (2006) Blue light inhibits stem elongation of chrysanthemum. Acta Hortic 711:363-367

Song YH, Ito S, Imaizumi T (2013) Flowering time regulation: photoperiod- and temperature-sensing in leaves. Trends Plant Sci 18:575-583

Takemiya A, Inoue S, Doi M, Kinoshitaa T, Shimazaki K (2005) Phototropins promote plant growth in response to blue light in low light environments. Plant Cell 17:1120-1127

Tewolde FT, Lu N, Shiina K, Maruo T, Takagaki M, Kozai T, Yamori W (2016) Nighttime supplemental LED inter-lighting improves growth and yield of single-truss tomatoes by enhancing photosynthesis in both winter and summer. Front Plant Sci 7:448

van Ieperen W (2012) Plant morphological and developmental responses to light quality in a horticultural context. Acta Hort 956:131-139

Zeevaart JAD (2008) Leaf-produced floral signals. Curr Opin Plant Biol 11:541-547

Publisher's Note Springer Nature remains neutral with regard to jurisdictional claims in published maps and institutional affiliations. 